\title{
MAESTROS Y ESCUELAS NORMALES EN EL CARIBE COLOMBIANO DURANTE EL RÉGIMEN FEDERAL ${ }^{1}$
}

\author{
Luis Alarcón Meneses ${ }^{2}$ \\ Universidad del Atlántico-Colombia \\ luchoalarconmeneses@gmail.com
}

Recepción: 27/03/2012

Evaluación: 09/04/2012

Aceptación: 29/05/2012

Artículo de Reflexión

doi: 10,9757

\section{RESUMEN}

Este trabajo da cuenta de uno de los principales actores del escenario escolar en Caribe colombiano: el maestro, quien ocupo un lugar central en el proyecto educativo propuesto por los liberales radicales durante el régimen federal. En efecto, para los liberales radicales la mejor forma de avanzar en la consolidación del régimen republicano pasaba necesariamente por el fortalecimiento de la instrucción pública, para lo cual era indispensable formar maestros en escuelas especializadas como las normales, las cuales también fueron establecidas en Cartagena, Santa Marta y Barranquilla durante la segunda mitad del siglo XIX. En efecto, las escuelas normales se constituyeron en el principal escenario educativo para la profesionalización del maestro, por lo cual historiarlas resulta clave para conocer las dinámicas de cómo se dio en la región el proceso educativo impulsado por los radicales, al mismo tiempo que ello nos transporta al interior del espacio escolar; es decir, más allá del discurso pedagógico y de la retórica de administradores y supervisores que muchas veces observaban las instituciones escolares desde afuera sin entrar en detalles sobre las prácticas educativas que allí tenían lugar.

Palabras clave: Revista Historia de la Educación Latinoamericana, maestros, escuelas normales, profesionalización docente, reglamento, Caribe colombiano, régimen federal.

\footnotetext{
Este artículo hace parte del proyecto de investigación "Escuela y prácticas educativas en el Caribe colombiano durante la segunda mitad del siglo XIX" realizado durante el año sabático concedido por la Universidad del Atlántico en el año 2010.

2 Doctor en Historia de la Educación UNED-España. Profesor Titular Programa de Historia/ Universidad del Atlántico. Director del Grupo de Historia de la educación e identidad Nacional. Editor revista Historia Caribe.
} 


\section{TEACHERS AND NORMAL SCHOOLS IN THE COLOMBIAN CARIBBEAN REGION DURING FEDERAL REGIME}

\begin{abstract}
This paper shows one of the main actors in the school scene of the Colombian Caribbean: the teacher, who played a major role in the educational project proposed by extreme liberals during federal regime. Indeed, for extreme liberals the best way to advance towards the consolidation of the republican regime had necessarily to make its way through the public instruction strengthening, to this end it was essential to grow teachers in specialized schools such as normal schools, which were also established in Cartagena, Santa Marta and Barranquilla during the second half of the 19th century. Certainly, normal schools were built in the main educational scene to make teachers professionals. Because of this, it is important to make a historical time line in order to know how were the dynamics of the educational process driven in the region by extremists and at the same time transport us to the core of educational space, i.e. beyond pedagogical speech, managers' and supervisors' rhetoric which sometimes it is observed by academic institutions from the outside; leaving a side the details about educational habits that took place.
\end{abstract}

Key words: Journal of Latin American Education History, teachers, normal schools, make teachers professionals, regulations, Colombian Caribbean, federal regime.

\section{PROFESSORES E ESCOLAS NORMAIS NO CARIBE COLOMBIANO DURANTE O REGIME FEDERAL}

\section{RESUMO}

Este trabalho dá conta de um dos principais atores do cenário escolar no Caribe colombiano: o professor, que ocupou um lugar central no projeto educativo proposto pelos liberais radicais durante o regime federal. Em efeito, para os liberais radicais, a melhor forma de avançar na consolidação do regime republicano passava necessariamente pelo fortalecimento da instrução pública, para o qual era indispensável formar professores em escolas especializadas como as normais, as quais também foram estabelecidas em Cartagena, Santa Marta e Barranquilla durante a segunda metade do século XIX. Em efeito, as escolas normais se constituíram no principal cenário educativo para a profissionalização do professor, o que significa que historiá-las consiste na chave para conhecer as dinâmicas de como se deu na região o processo educativo impulsionado pelos radicais, ao mesmo tempo em que ele nos transporta ao interior do espaço escolar, isto é, para além do discurso pedagógico e da retórica de administradores e supervisores que muitas vezes observavam as instituições escolares a partir de fora, sem entrar em detalhes sobre as práticas educativas que ali aconteciam.

Palavras-chave: Revista História da Educação Latino-americana, professores, escolas de formação de professores, profissionalização docente, regulamentação, Caribe colombiano, regime federal.

\section{INTRODUCCIÓN}

En el Caribe colombiano la escuela, entendida como espacio de intermediación sociocultural, fue escenario de un conjunto de normas que tenían como objetivo, además del ideal organizativo, el establecimiento de los saberes a enseñar y de los comportamientos a infundir en los niños y jóvenes que a ella asistían. También sería el entramado de una serie de "ensayos pedagógicos" a través de los cuales se pretendió educar al pueblo en los nuevos valores del régimen republicano. 
En términos del historiador Dominique Julia ${ }^{3}$, la escuela sería el epicentro de la llamada "cultura escolar", entendida ésta, en palabras de Antonio Viñao, como "un conjunto de teorías, ideas, principios, pautas, rituales, inercias, hábitos y prácticas sedimentadas a lo largo del tiempo en forma de tradiciones, regularidades y reglas de juego no puestas en entredicho, y compartidas por sus actores, en el seno de las instituciones educativas"4. Ciertamente, la escuela existente en las poblaciones de la región durante la segunda mitad del siglo XIX, aún en medio de sus carencias, se constituyó en un espacio que, además de heredar las tradiciones educativas del mundo moderno, trató de implementar las nuevas condiciones organizativas y pedagógicas impuestas por el régimen radical, al mismo tiempo que debió amoldarse a las particularidades sociales y culturales propias de la región en la cual se encontraba. Es decir, en la escuela, como espacio de mediación cultural, confluyeron las prácticas culturales propias de los imaginarios sociales tradicionales de la época y las nuevas formas de actuación requeridas por el proceso de modernización de la sociedad colombiana impulsado por el liberalismo radical.

Este artículo intenta identificar y analizar algunos de los principales aspectos constitutivos de la cultura escolar propios de las escuelas de la región, lo cual necesariamente implica ocuparse de uno de los principales actores del escenario educativo, como en efecto lo ha sido el maestro, quien conjuntamente con alumnos, padres de familia y funcionarios, entre otros, contribuyó a conformar una cultura escolar integrada también por los discursos relativos a las prácticas pedagógicas, así como por los contenidos curriculares, asignaturas, métodos de enseñanza, mecanismos de control y vigilancia escolar, modos de evaluación utilizados en escuelas cuyo principal objetivo fue "disciplinar al bárbaro" para convertirlo en el ciudadano requerido por la república.

\section{El maestro: entre el imaginario y la realidad}

"Ser modelo de virtud, de decoro y buenos modales para los alumnos, y procurar de un modo persistente que sus alumnos adquieran hábitos en ese sentido [...] que el maestro de escuela, como el sacerdote y el hombre de estado, ha de obrar sobre el espíritu y la conducta de sus subordinados”. Así

3 Julia, Dominique. "La culture scolaire comme objet historique", en: The Colonial Experience in Education, Historical Issuesand perspectives, Paedagogica Historica. Supplementary Series Volume I eds. Antonio Nóvoa, Marc Depaepe y Erwin Johanningmeier (Belgica, CSHP, 2009), 353-382.

Antonio Viñao Frago, Sistemas educativos, culturas y reformas (Madrid: Ed. Morata, 2009), 73.

Magadly Téllez, "Disciplinar al Bárbaro que se llevaba adentro. Un acercamiento a la ley del buen ciudadano del siglo XIX", Historia Caribe No. 10, (2005), 96-110. 
definía el Reglamento de Instrucción Pública Primaria del Estado de Bolivar el perfil del maestro de escuela. Este documento hacía énfasis en un tipo de maestro conservador de las buenas costumbres y celoso guardián del orden establecido, cuya principal virtud debía ser la de un individuo capaz de guiar a sus alumnos dentro del ideario de la moral republicana. Es decir, su rol apuntaba a formar, se asociaba al de un agente de formación y control ciudadano.

El mismo reglamento hacía énfasis en que la figura del maestro debía estar asociada al de una persona instruida, formada personal y profesionalmente en los saberes que debía enseñar. Sobre todo insiste en la figura del maestro como modelo para alumnos y población. En el artículo 40 ordena que el maestro no debe relacionarse jamás con personas de "mala fama", no concurrir a establecimientos de juego, a tabernas y venta de licores, ni a ninguna "casa mal reputada", a lo cual agrega la prohibición de embriagarse o de participar en escándalos públicos.

Este tipo de reglamentación de la labor docente mostraba más preocupación por las condiciones morales y el comportamiento del maestro que por sus capacidades en cuanto a saberes y conocimientos disciplinares y pedagógicos. Se pretendía contar con personas que a través del ejemplo influyeran positivamente en la formación de niños y jóvenes dentro de los nuevos valores de orden republicano. Por esta razón se recomendaba al maestro ser fuente de inspiración de sus alumnos y enseñarles "amor y temor a Dios", así como "amor a la virtud y a la Patria, respeto a la ley y a las autoridades, fidelidad en el cumplimiento de los deberes que más tarde tendrán como ciudadanos de una república, amor a la verdad y a la justicia y consagración al trabajo"x.

Este ideal del maestro, a pesar de estar contenido en un reglamento expedido a fines del período federal, cuando ya los liberales radicales habían sido desplazados del poder por parte de los regeneradores, era muy similar al incluido en los reglamentos expedidos en pleno auge del radicalismo, como efectivamente ocurrió con el Estatuto de la Escuela Pública del Distrito Municipal de Río de Oro, en el Estado del Magdalena, el cual consideraba que el maestro debía sobre todo "inspirar a los alumnos respeto a la religión, obediencia a la ley, amor a la virtud y a la libertad, entusiasmo por la gloria, adición a la patria, horror al crimen, aborrecimiento al vicio, compasión por la desgracia y en una palabra educar al corazón del niño haciéndolo pasar por sus consejos inspirándole gran cariño por la verdad única siendo que conduce al templo de la sabiduría".

\footnotetext{
6 "Reglamento de la Instrucción Pública Primaria en el Estado de Bolívar", Cartagena, Tipografía de Antonio Araujo, 1886, Archivo Histórico de Cartagena (AHC), 27.

"Acuerdo del Cabildo Distrital de Río de Oro". Agosto 30 de 1868. Santa Marta, Archivo Histórico del Magdalena. (AHM), Caja 013. leg. 012, f. 5.
} 
Esta reglamentación, además de mostrar las imágenes y representaciones construidas por parte de la sociedad regional en torno a la figura ideal del maestro, constituye también en un indicador de la existencia de esta profesión, la cual ya desde comienzos del siglo XIX había dejado de ser tan solo un oficio para transitar hacia su profesionalización, proceso al cual contribuyó la creación, por parte de los gobiernos radicales, de las Escuelas Normales. Es decir, a pesar que en algunos pueblos todavía ejercían los viejos maestros que hacían parte del gremio profesoral, la labor de maestro era ya una profesión que a mediados del siglo XIX estaba, por lo menos formalmente, bajo el control del Estado, tal como lo muestran las condiciones exigidas por una normatividad dirigida a que el maestro como ciudadano ejemplar tuviese un comportamiento probo y buenas aptitudes morales. El institutor, además de profesar cariño por lo niños e interés por su suerte, "debe ser abnegado, paciente, sobrio, dulce, sencillo, de intachable integridad moral, enérgico en sus resoluciones, de espiritu vivo y vigoroso, de clara inteligencia, perspicaz, para comprender los caracteres y aptitudes de sus alumnos, flexible para dirigir a cada uno según sus inclinaciones: debe comprender el alcance de su misión y seguirla cono un sacerdocio o postulado's.

Sin embargo, a pesar de la profesionalización de la actividad docente, la realidad mostraba una presencia exigua de maestros, tal como lo señalan las constantes quejas a través de las cuales se informa que '[...] no hay personalpara elegir los maestros idóneos necesarios"; razón por la cual en varias poblaciones de la región no pudieron abrirse escuelas y en otras debieron acudir a personas con exigua preparación para evitar el cierre de estas escuelas: "[...] quien hace las veces de maestro a penas sabe leer y escribir, pero desconoce totalmente el manejo de los números $" 10$. Los escasos y mal preparados maestros enfrentaban además el problema de la falta del pago oportuno de un salario considerado muy bajo para la época, lo cual desestimulaba a quienes querían vincularse a la labor docente, aunque fuera sólo por el interés de hacerse a un empleo en una sociedad donde las oportunidades labores eran casi inexistentes.

'Las dotaciones [salariales] señaladas a la penosa labor de los maestros no ofrece aliciente a los que a ella se dedican; y hasta disculpan la poca contracción de algunos y hasta que emprendan simultáneamente otros trabajos que permitan hacer frente a la subsistencia [...] Semejantes sueldos principalmente tratándose de padres de familia son insuficientes y tampoco son recompensa bajo ningún respeto para un trabajo de todas las horas, ni remuneración digna del empleo de aptitudes notables adquiridas a consideración de notables gastos y de largos años de estudio y de

\footnotetext{
8 "Informe del Director General de Instrucción Primaria de la Unión", Bogotá, Imprenta de Medardo Rivas, 1876, Biblioteca Nacional de Colombia. (BNC), 191.

9 "Informe del Alcalde de Tenerife", 22 abril de 1869, Santa Marta, AHM, Caja 12-1869, legajo 2, f. 3.

10 "Informe del Alcalde de Tenerife", f. 3.
} 
aplicación. Los que poseen estas últimas fácilmente encontrarán siempre ocupación más provechosa para si mismos y para su familia; y en tal situación los encargados de dar impulso a la instrucción tienen que escoger entre la aceptación de malos maestros, o la clausura de la mayor parte de las escuelas"11.

Lo anterior muestra la precariedad económica que enfrentaban quienes se desempeñaban como maestros, quienes a pesar del reconocimiento obtenido ante sí mismos y ante otros sectores de la población, ello no estuvo acompañado de una retribución digna, de una mejor condición de vida o de una valoración más profunda de su labor por parte del Estado. En efecto, mientras que por un lado se desplegaba un discurso de idealización del maestro y se le asignaba la responsabilidad de formar ciudadanos, por otro lado, el Estado no le reconocía un sueldo proporcional a su labor educadora, a la cual se le considerada como vital para la transformación de la sociedad republicana.

Los bajos sueldos fueron determinantes en las condiciones de vida de los maestros, la cual para el caso de los Estados de la costa estaban en correspondencia con las condiciones generales de la instrucción pública. Como ya anotamos en el capítulo anterior, ella no contaba con los recursos suficientes para el pago de los salarios a los maestros, circunstancia que llevó a los habitantes de algunas poblaciones a recoger dinero entre ellos y ofrecerle al maestro un pago extra para que éste aceptara el cargo y no terminara marchándose como sucedía a menudo en la mayoría de pueblos, tal como se puede apreciar en las palabras del Gobernador Verbel referidas al distrito de Sampués:

"Los padres de familia comprendiendo que el poco sueldo señalado al director pudiera ser causa para que el Sr. Anachuri no fuera hacerse cargo del destino, me autorizaron para que ofreciera a dicho señor un sobre sueldo de veinte pesos que pagarian ellos; $y$ aun con ese aumento no se ha decidido, teniendo en consideración que el sueldo principal tendrá que venderlo por la mitad de su valor, por el retardo con que los sueldos se pagan"'s.

A los exiguos salarios y la carestía que enfrentaba el preceptor de la escuela pública, se sumaba el problema del retraso en el pago de sueldos, lo cual agravaba mucho más su condición. Si el maestro quería sobrevivir, debía acudir a los prestamistas locales, quienes, aprovechándose de la situación cobraban un interés del $50 \%$, lo cual acababa empeorando las ya pobres condiciones económicas del maestro: [...] el pago de las asignaciones de que gozan

\footnotetext{
11 "Informe del Director de Instrucción Pública del Estado de Bolívar", Cartagena, (AHC), 27 de julio de 1878.

12 "Informe del Gobernador de la Provincia de Sincelejo", Cartagena, (AHC), 15 de julio de 1876.
} 
se verifica con retardos considerables, dando asi margen a que se enriquezcan los agiotistas con el sudor de los pobres empleados públicos"13.

Esta situación no se presentaba sólo en los Estados costeños: estos problemas de orden financieros de la instrucción pública y los consuetudinarios atrasos en el pago a los maestros también se dieron en otros Estados de la Unión, tal como lo registró para el caso de Bogotá el viajero suizo Ernest Röthilisberg:

"En dicho Estado de Cundinamarca se adeudaba a los maestros en 1884 casi año y medio de sueldo, de manera que la mayor parte de ellos, aunque por sentido del deber siguieron trabajando en sus escuelas, se veian obligados a buscarse otras ocupaciones. Las letras de cambio con que se les pagaron algunos meses, sólo podían hacerse efectivas acudiendo a los usureros. No puede sorprender, pues, que resultara dificil sostener los centros de formación de maestros y maestras, cuanto más que la mala administración del Estado hacía imposible cubrir con regularidad todas las obligaciones al respecto"'14.

Los bajos salarios y el atraso de los mismos llevaron a la gran mayoría de maestros a dedicarse simultáneamente a otras actividades para obtener ingresos extras. Algunos se dedicaban a contrabandear licores, al cultivo de productos agrícolas de pan coger o abrir tiendas de abarrotes, lo cual reducía el tiempo dedicado a sus labores en la escuela. Situación denunciada por quienes consideraban que:

"El profesorado es de aquellas ocupaciones que quitan al hombre que quiera desempeñarlo bien todo el tiempo que pudiera destinar a otro tipo de trabajos, y los ponen en la obligación de hacer ciertos gastos inherentes a ella; por consiguiente el maestro de escuela debe contar con una renta que lo alague [sic] no solo por su buena dotación sino por la puntualidad en su pago; y entonces solo pueda dedicarse a enseñar a sus alumnos; pero con sueldos exiguos y pagados con demasiada demora no habrá autoridad tal que le permita hacer tal exigencia a ningún director, ni menos exigir que se distraiga su atención en cualesquiera otro tipo de trabajos como ordinariamente sucede" ${ }^{\prime \prime}$.

Al tiempo que se reconocía el compromiso del maestro y su dedicación para con la escuela, en la práctica se aceptaba que realizara otras actividades para aliviar la penuria económica en medio de la cual vivía. Ciertamente, el

13 "Informe de Instrucción Pública. Informe anual del Rector del Colegio", en Diario de Bolivar, Cartagena, 16 de Julio de 1875.

14 Ernst, Röthlisberger. El Dorado, (Bogotá: Biblioteca V Centenario Colcultura, 1993), 168.

15 “Informe del Gobernador de la Provincia de Sincelejo, 1875", en Diario de Bolivar, Cartagena 9 de agosto de 1875. 
maestro de la época por lo general era un individuo perteneciente a las capas medias de la sociedad cuyas familias no poseían mayores riquezas, razón por la cual veían en esta profesión una posibilidad de alcanzar un empleo como servidor público, que permitiría a muchos hombres y mujeres, aún a pesar de los bajos e irregulares salarios, alcanzar un nuevo estatus social.

En la segunda mitad del siglo XIX, ser maestro continuaba siendo una opción para salir de las dificultades económicas que enfrentaban las familias, incluso de aquellas que en algún momento habían tenido una buena posición económica y que habían caído en la quiebra. Por esta razón algunos jóvenes eran postulados por sus padres o mentores políticos para ingresar a las recién establecidas Escuelas Normales para formarse como maestros de escuela, solicitudes que en muchas ocasiones eran aceptadas debido al escaso número de individuos postulados. Como resultado, en las Escuelas Normales existentes en el país durante el régimen radical, la deserción por falta de vocación y bajo rendimiento era una constante. Sin embargo, esto no impediría que muchos jóvenes sin ninguna aptitud por la enseñanza culminaran sus estudios convirtiéndose así en maestros de escuelas públicas con lo cual pretendían garantizarse "una colocación lucrativa [...] y obtener por cierto número de años alimentos y babitación a expensas del erario público"16.

Muchas de las postulaciones de becas para ingresar a las Escuelas Normales de maestros no se sustentaban en el talento o en el deseo de ilustración de los jóvenes sino en otro tipo de argumentos como la extrema pobreza, las relaciones de parentesco o amistad con los funcionarios del Estado y por los "servicios políticos" que la familia del aspirante había realizado a favor del gobernante de turno; práctica que fue denunciada por Enrique Cortés, Secretario de Instrucción Pública Primaria de la Unión en 1876, para quien no se justificaba que "las gentes no se penetraran de que la Escuela Normal no es un instituto de caridad, sino laboratorio en que se fabrican sacerdotes para que formen el corazón y la cabeza de las generaciones futuras" "17.

Las reiteradas críticas por la escasa vocación de quienes ingresaban a la Escuela Normal solo con la intención de acceder posteriormente a un contrato laboral como maestros, evidencian una práctica que terminó por ser habitual en la región durante la segunda mitad del siglo XIX, tal como lo demuestra la carta enviada por Idelfonso Soto al Presidente del Estado de Bolívar, en la cual, al reclamar un puesto como maestro, deja ver cómo

16 "Informe del Director General de Instrucción Primaria de la Unión", Bogotá, (BNC), Imprenta de Medardo Rivas, 1876, 191.

17 Informe del Director General de Instrucción Primaria de la Unión”, 191. 
esta profesión se convirtió en una manera de superar la falta de trabajo que aquejaba a la juventud:

"Insisto señor en aspirar al nombramiento de una escuela; porque aun soy joven, me siento capaz para cumplir con las importantes obligaciones que contraigo con la sociedad, al dedicarme a formar hombres útiles para ella; y además por que el gobierno del Estado al arrancarme de los brazos de mi familia para que recibiera la instrucción complemental, me cerró las honradas puertas del artesano; asi es que acobardado por la merecida deferencia que se ha becho en mi opositor en la escuela elemental, me retirara en busca de una profesión, creedlo: solo hallaría la osociedad [sic] y después...... la corrupción! No me atrevo siquiera a sospechar que el Ciudadano Presidente quiera cortar las alas de la juventud que hoy se levanta ambiciosa de contribuir por su parte al engrandecimiento de su patria"rs.

Evidentemente la profesión de maestro de escuela, a pesar de los problemas de orden salarial, era un mecanismo de ascenso social que permitía a algunos sujetos abrirse espacio en la sociedad local y entrar a disputarles el protagonismo a otros actores de la vida municipal: el cura, el alcalde, el juez y el gamonal, quiénes debieron acostumbrarse, en ocasiones no con muy buena voluntad, a una figura que para el proyecto político radical fue fundamental en el proceso de construcción de una sociedad republicana moderna y constituida por ciudadanos formados en la escuela pública bajo la orientación del preceptor egresado de las Escuelas Normales, creadas desde 1872 en cada una de las capitales de los nueve Estados soberanos para constituir una legión secular de preceptores capaz de asumir los nuevos retos de la modernidad.

\section{La Escuela Normal como espacio para la formación del maestro}

La estatalización de la formación de maestros ocupó un lugar principal en la agenda educativa del liberalismo radical, tal como lo demuestra la reforma de 1870, para la cual la formación de maestros se convirtió en objetivo primordial. Para lo cual se diseñaron tres proyectos estrechamente relacionados: la creación de las escuelas normales en cada uno de los Estados soberanos, la contratación de maestros alemanes para dar forma a lo que se llamó Misión pedagógica Alemana y, por último, la publicación de periódicos y revistas de carácter instruccionista. Los liberales radicales consideraban que la suma de estas acciones era la clave para lograr sus propósitos en el campo educativo. Ciertamente, estas condiciones eran necesarias para mejorar la cobertura y el Sistema de Instrucción Pública, el cual exigía un cuerpo profesoral capacitado y formado para asumir la educación de niños en el nivel primario.

18 La Revista, Cartagena, Secretaria de Instrucción Pública del Estado de Bolívar, 1872, No. 1, 5 
Para cumplir con este ideal, los liberales radicales instituyeron, a través del Capítulo VII del Decreto Orgánico de Instrucción Pública de 1870, la creación de Escuelas Normales en las capitales de cada uno de los Estados Soberanos para "formar maestros idóneos que regentaran las escuelas elementales y las superiores". Así mismo, a través de otras acciones legales se asignaron presupuestos, definieron planes de estudio, horarios de asistencia a clases y procesos administrativos de las Escuelas Normales.

Con la apertura de las Escuelas Normales se buscaba consolidar un grupo de maestros especializados en las teorías pedagógicas de moda en Europa, quienes luego debían vincularse a las escuelas públicas y fomentar en ellas la formación ciudadana requerida por la república moderna y consolidar el modelo Estado nación de corte liberal, situación que generó la oposición de la Iglesia y de los conservadores quienes consideraban que con ellas se usurpaban las tradiciones y creencias del pueblo colombiano el cual, según ellos, corría peligro ante la presencia de un Estado moderno y secularizado ${ }^{19}$.

Sin embargo, la aplicación de esta disposición de orden nacional sólo se daría a partir de 1872, año en el cual se abrieron varias escuelas normales en los Estados de Santander, Boyacá y Magdalena. En este último, el Presidente del Estado tomó la bandera para crear la Escuela Normal de Varones en Santa Marta y dar así cumplimiento al proyecto impulsado y avalado por el gobierno central, presidido por el presidente Eustorgio Salgar, quien, para hacerlo realidad, contrató la primera misión pedagógica alemana para establecer en las escuelas normales el entrenamiento de los instructores de acuerdo con los métodos pestalozzianos. En esta misión arribaron al país nueve pedagogos alemanes quienes fueron distribuidos en cada uno de los Estados: Gotthol Weis en el Estado de Antioquia; Julio Wallner en Bolívar; Augusto Pankau en Cauca; Carlos Meisel en Magdalena; Ofrald Wirsing en Panamá; Alberto Blume en Cundinamarca; Gustavo Radlack en el Tolima; Ernesto Hotschick en Boyacá y Carlos Uttermann en Santander.

De los nueve pedagogos alemanes, 7 eran protestantes y dos católicos. Estos últimos fueron vinculados a los Estados de Antioquia y Tolima los cuales estaban controlados por gobiernos conservadores que habían exigido al gobierno federal de Eustorgio Salgar la vinculación de maestros de filiación católica para que hubiese así concordancia con las tradiciones y la fe del pueblo antioqueño y tolimense. La llegada de la misión alemana fue el resultado de un

19 Miguel Antonio Caro. "El derecho de definir", en: Anales religiosos de Colombia, eds. Ministerio de Educación Nacional. (Bogotá: Biblioteca Popular, 1884), 406-431 
proceso de consulta previa de los sistemas educativos existentes en Europa y Estados Unidos, realizado por los cónsules colombianos en estos países, previa solicitud del gobierno nacional. Este se decidió por los alemanes ya que éstos eran partidarios del método propuesto por J.H. Pestalozzi, práctica pedagógica aceptada tanto por liberales y conservadores. Los primeros la consideraban adecuada porque con ella se proveía de disciplina y eficacia para alcanzar un mejor acceso a la lectura, fundamentos claves para la formación del ciudadano elector. Por su parte, los conservadores veían la utilidad del método en la medida en que su eficacia se apoyaba en una férrea disciplina y en principios confesionales de carácter religioso. ${ }^{20}$

Sin embargo, la vinculación de los maestros alemanes generó un rechazo por parte de la Iglesia y de los dirigentes conservadores. Quienes, como en el caso del obispo de Santa Marta José Romero, calificaron de protestantes, inmorales e ignorantes de la realidad colombiana a los profesores traídos de Alemania por el gobierno radical.

\begin{abstract}
"¿Qué hacer cuando vemos llegar lobos rapaces para que descarrien el rebaño de Jesucristo y a quienes se les entregaran los pequeñuelos para que los lleven a beber en la fuente impura del protestantismo? ¿Qué hacer, levantar la vozpara excitar a nuestro clero se muestre vigilante y redoble sus esfuerzos en la lucha que se continua bajo otro sistema contra la religión que, descendida del cielo, nos legaron nuestros padres?"'?1.
\end{abstract}

Simultáneamente, el ideólogo conservador Miguel Antonio Caro, consideraba que la misión alemana no era otra cosa que una conspiración para invadir el país de protestantes y hacerle la guerra a la Iglesia católica. Consideraba a ésta como la legítima responsable de formar los espíritus de los niños y jóvenes que asistían a la escuela. Para evitar la supuesta conspiración, la élite antioqueña trajo a dos maestros católicos contratados directamente por el Estado federal, quienes se sumaron a Gotthol Weis contratado previamente por el gobierno nacional.

En cumplimiento del decreto orgánico de instrucción pública, se abrieron en Cartagena y Santa Marta las respectivas Escuelas Normales adscritas a los Estados costeños. En Santa Marta la Escuela Normal del Magdalena abrió sus puertas el 1 de junio de 1872 en la casa de Juan Bautista Abelló, ubicada en la calle de la Cruz. En diciembre de ese mismo año, se elaboró y publicó

20 Gilberto Loaiza Cano, "El maestro de escuela o el liberal del ciudadano en la reforma educativa de 1870", en, Historia Critica, No. 34, (2007), 73.

21 Cartas, (Santa Marta, 1872), en Archivo Episcopal de Santa Marta (AES), Tomo 90, folio 110. 
la reglamentación de la Escuela Normal de Santa Marta, la cual en sus inicios estuvo bajo la dirección del maestro alemán Carlos Meisel. El reglamento establecía como objeto "A la vez que formar hábiles y competentes maestros hacer ciudadanos que sirvan de modelo a sus semejantes y hombres que por su pureza de sus costumbres lleguen al desarrollo completo de todas sus facultades"22. Por tanto se exigía a los maestros una doble misión que incluyera tanto la "prolija y bien dirigida enseñanza de los diferentes ramos" como enseñar la "moralidad y patriotismo"23.

Por su parte, la Escuela Normal del Estado de Bolívar inició labores en 1872 en la misma edificación en la cual funcionaba el colegio del Estado, situación que desde un principio se convirtió en un problema ya que se presentaban altercados de orden administrativo por la distribución de los espacios para las dos instituciones que allí funcionaban, razón por la cual se insistía en la necesidad de independizar las dos escuelas para evitar así el ambiente de promiscuidad que allí reinaba y evitar los altercados que atentaban contra el nuevo sistema de instrucción pública del Estado ${ }^{24}$.

Las primeras plazas para alumnos-maestros de la Escuela Normal del Estado de Bolívar fueron convocadas por Mauricio Verbel, director de instrucción pública del Estado, el 25 de noviembre de 1873. El objetivo era seleccionar 12 jóvenes para que perfeccionaran su educación técnica y metodología, para lo cual se les exigía cumplir con algunos requisitos como "tener 18 años cumplidos, poseer buena conducta, no sufrir enfermedad contagiosa o repugnante" 25 . Los escogidos como alumnos-maestros por parte del Estado tenían derecho a habitación, alimentos, asistencia doméstica, enseñanza y uso de los útiles.

Antes de matricularse los estudiantes se les daba a conocer el reglamento interno, el cual estaban obligados a cumplir mediante la firma de unas escrituras al momento de matricularse. Por ejemplo, se debían mantener una actitud de obediencia con sus superiores, evitar la visita a casas de juego, evitar el consumo de bebidas y tabaco, se describían las designaciones de "Celador" y "Semanero" como cargos otorgados a aquellos estudiantes que demostraran buena conducta, designaciones que les permitían ejercer cierta autoridad sobre sus compañeros. Finalmente se distribuía el tiempo de las diferentes actividades realizadas a lo largo de todo el día.

\footnotetext{
Archivo Histórico del Magdalena (AHM), (Santa Marta, 1872). Caja No 8.

Cartas, (Santa Marta, 1872), en Archivo Episcopal de Santa Marta (AES), Tomo 90, folio 110.

Gaceta de Bolivar, Cartagena, 24 de octubre de 1874. No. 974, 136

Gaceta de Bolivar, Cartagena, 25 de noviembre de 1873, No. 879, 170.
} 
También era necesario que la Escuela Normal tuviera su escuela anexa, especificando las asignaturas que deberían enseñarse en cada una de estas instituciones. En la primera se cursaba pedagogía, la asignatura de mayor intensidad, enseñanza, escritura, dibujo, canto, geometría, historia nacional, gimnasia, aritmética, composición, gramática, física y geografía. En la Escuela Anexa, por su parte, se estudiaba aritmética, enseñanza, geometría, escritura, dibujo, canto, historia patria, gramática, lectura, composición y dibujo.

La Escuela Normal de Bolívar, que funcionaba en Cartagena, estaba dirigida por el maestro alemán Julio Wallner, de quien algunos dirigentes cartageneros tenían la mejor impresión, pues lo consideraban "un hombre honrado a carta cabal, quien conocia perfectamente su profesión de institutor pestaloziiano, la cual habia practicado durante varios años en las escuelas públicas de Prusia, teniendo de su habilidad pedagógica, conocimientos científicos [...] ${ }^{126}$.

Para el segundo semestre de 1874, casi un año después de su apertura, la Escuela Normal de Bolívar dirigida por Julio Wallner, contaba ya con 28 alumnos divididos en tres cursos de acuerdo con el nivel alcanzado en las pruebas. Ésto permitió al director detectar la presencia de estudiantes sin vocación por la profesión de maestros y a quienes consideraba como un grupo "de individuos que, ineptos para el magisterio, han tomado la Pedagogía como una especulación. Estos señores cometen un crimen de lesa patria; como que haciéndole perder a la juventud su tiempo más precioso, defraudan el porvenir de la República, que nos pertenece; y lo que no nos pertenece debe sernos sagrado"27.

Además de lidiar con estudiantes sin vocación y muy mal fundamentados en los conocimientos elementales, las Escuelas Normales de la costa debieron afrontar los mismos problemas de la educación en la región, entre los cuales el aspecto financiero ocupaba el primer lugar. Así lo informó en su momento el mismo Julio Wallner, para quien la marcha de la escuela estaba obstaculizada por dificultades de distinto tipo, al punto que ésta carecía de los elementos indispensables para su desarrollo, tales como maestros, mobiliario, útiles, textos y espacios adecuados para su buen funcionamiento. Lo anterior llevó a su director a quejarse por esta situación, especialmente la relacionada con la ausencia de manuales escolares:

"Tengo el honor de llamar su atención con la presente nota para que se sirva dirigirse de nuevo al Gobierno nacional, requiriendo los textos necesarios para los estudios de los alumnos de esta Escuela. Es sumamente difícil practicar el servicio de

\footnotetext{
Gaceta de Bolívar. No. 800, 4.

Gaceta de Bolívar, 4.
} 
enseñanza y procurar el desarrollo del Instituto, sin los medios más indispensables, pues los alumnos no tienen recursos para facilitárselos; y sabiendo notoriamente que el Gobierno nacional los ha proporcionado a todas las Escuelas Normales de la Nación, creen ellos que es justo que deban ser protegidos por él de igual manera. Ruego a U. por tanto, se sirva lo más pronto llamar la atención del Gobierno nacional hacia esta grave falta, por lo cual todos sufrimos, tanto los superiores como los alumnos"'28.

Debido a lo limitado de sus recursos las Escuelas Normales funcionaron con cierta irregularidad durante la década de 1870. Situación que se agravó durante los años 1876 y 1877 cuando debieron ser cerradas por la guerra civil que se sufría en el país.

"Los años escolares de 1876 y 1877 deben considerarse perdidos para la Escuela Normal, la cual estuvo clausurada por orden del poder ejecutivo nacional por más de un año y medio. Varios alumnos cambiaron entonces el libro por el fusily lucharon en los campos de Piaurichon por las libertades públicas"'29.

Un año antes de la guerra civil de 1876, se decretó la creación de las escuelas normales femeninas de Santa Marta y Cartagena. La primera estuvo dirigida en sus primeros años por la maestra alemana Elizabeth Meisel, esposa de Carlos Meisel, quien había sido contratado en Alemania por el gobierno nacional para dirigir la Escuela Normal de Varones del Magdalena. En las Normales Femeninas básicamente se formarían las jóvenes de clase baja para que se vincularan como profesoras. Por ello se les enseñaba el mismo plan de estudios diseñado para las escuelas de varones, adicionándoles urbanidad, costura, economía doméstica y medicina casera.

En 1876, mediante la Ley 45 del 2 de Junio, se ordenó la apertura de nuevas Escuelas Normales y superiores de varones por fuera de las capitales de los Estados costeños. Para ello se escogieron, en el caso del Magdalena, los Distritos de Remolino, Aguachica y San Juan del Cesar, asignando el presupuesto necesario para su funcionamiento mediante su inclusión dentro del presupuesto nacional. Sin embargo, y debido a la guerra que se desató ese año, éstas no pudieron funcionar.

Luego de la guerra civil de 1876-1877, el gobierno nacional, con el fin de incrementar el número de profesores formados, continuó con el programa

\footnotetext{
28 "Informe anual del Director de Instrucción Pública de Bolívar, 1874", en Gaceta de Bolívar. Cartagena, 14 de Septiembre de 1874.

29 "Secretaria de Instrucción Pública del Estado del Magdalena", en El Institutor, Santa Marta, 15 de marzo de 1880, No. 2, 5 .
} 
de becas para que jóvenes de los distintos Estados estudiaran en las Escuelas Normales. Este incentivo de las becas se enmarcaba dentro de la política de masificación de la educación y las necesidades políticas de los radicales. A cambio, el alumno-maestro adquiría el compromiso de enseñar, durante cuatro años, en las escuelas oficiales. Con ello se pretendía que los profesores imbuidos de ideas modernas y de las teorías pedagógicas de Pestalozzi y Fröebel, contribuyeran a formar nuevos ciudadanos creyentes de la civilidad y la libertad liberal.

La medida también incluía a jóvenes de los llamados territorios nacionales. Por esto, el 9 de Abril de 1873 se expidió la ley 25 por medio de la cual la nación asumía los gastos que implicaran el estudio de hasta tres jóvenes de cada uno de los territorios nacionales en las Escuelas Normales. El número de jóvenes se fijaba teniendo en cuenta la densidad demográfica. Además se dejaba en manos del ejecutivo la reglamentación de las condiciones que debían cumplir los jóvenes, de la autoridad responsable de los nombramientos de los estudiantes y de la selección de la Escuela Normal a la que asistirían. Con respecto al presupuesto necesario para estas becas, se dispuso de lo asignado a la instrucción primaria y se complementaba con un "crédito suplemental".

La ley tendría una vigencia de seis años, esto es, hasta 1879, año en el cual se modificó de tal manera que el número de estudiantes por cada uno de los territorios nacionales ascendió a 6, con la particularidad de que se repartían entre hombres y mujeres. La prestación de servicios como institutores, una vez terminaran sus estudios, seguía vigente ${ }^{30}$.

Sin embargo, a pesar de los recursos recibidos para sufragar los costos de estudiantes becados, el funcionamiento de las Escuelas Normales de los Estado de Bolívar y Magdalena fue irregular, ya que debieron enfrentar, al igual que el resto del sistema escolar, las penurias económicas y los conflictos sociales y políticos que afectaban la Costa Caribe colombiana. Estas instituciones, a pesar de haber sido creadas formalmente en 1872 y 1873 respectivamente, enfrentaron diversos problemas para iniciar labores, tales como la falta de mobiliario y dotación, así como la poca recepción que ésta tuvo inicialmente en la juventud, la cual no se mostró interesada en seguir la carrera docente. Ante la falta de alumnos, las directivas de Instrucción Pública optaron por la apertura de Escuelas Anexas con el fin de preparar a los alumnos para la Escuela Normal. Sin embargo, unos meses después, para el caso del Magdalena esta debió cerrarse debido a las epidemias que durante

$30 \quad$ Véase: Leyes de Colombia. Bogotá, Imprenta Nacional, año 1879. 
los meses de septiembre y octubre mermaron la población infantil en Santa Marta: "[... una epidemia mortifera, sobre todo para la juventud, desoló los claustros de la escuela, haciendo victimas día por día’31.

En el Magdalena, la apertura y puesta en funcionamiento de la Escuela Normal sólo fue posible en 1873, gracias a la gestión de Luis Antonio Robles, quien desde la Dirección de Instrucción Pública del Estado impulsó este proyecto de formación de maestros, que contó inicialmente sólo con seis alumnos maestros internos, costeados por la nación y con otro grupo de alumnos externos que según el Director de la escuela poco aprovechamiento alcanzaron debido a su irregular asistencia y disciplina. Es de anotar que a pesar de que la nación se comprometía a costear 12 alumnos internos ello no fue posible debido a lo reducido de los recursos aportados por ésta, tal como lo manifestó en su momento Luis A. Robles al Director General de la Instrucción Pública:

"No quiero desaprovechar esta oportunidad para manifestar a usted que es sumamente reducido el número de alumnos de la Escuela Normal de este estado, y que apenas vale la pena de costear el establecimiento para sostenerlos. Verdad es que aqui los 12 alumnos constarian precisamente el doble que en los demás estados, por circunstancias especiales del país y sobre todo de la ciudad capital; pero también es cierto que si lo que se quiere es establecer igualdad, desigualdad habrá, muy grande $y$ dentro de poco tiempo, porque mientras la Nación dota a los otros estados con 12, 24 y 36 institutores, al Magdalena lo dotara solamente con 6, 12 o 18, siendo como es aqui en donde más necesidad se siente de maestros, porque como lo verá usted en las observaciones al cuadro que encontrará enseguida, muchas escuelas dejaron de funcionar por falta de Directores, siquiera medianos" ${ }^{\prime 32}$.

Este tipo de clamores muestran cómo la región Caribe recibía menor atención del gobierno nacional en el campo educativo, lo cual se hizo extensible a otros ramos de la inversión oficial. Situación que se mantendría durante el siglo XIX y que en la práctica se constituyó en uno de los elementos que impediría el desarrollo de la región en el campo educativo y social.

A pesar de las limitaciones financieras, la Escuela Normal del Magdalena logró graduar el primer grupo de alumnos maestros a fines de 1874. De este grupo, de 5 estudiantes hacían parte Gabriel Zúñiga, Juan Cayón, Lorenzo Torres, Leocadio Campo y José de la Cruz Díaz Granados, de los cuales solo 4 fueron vinculados como maestros en las escuelas de Riohacha, Santa Marta, Remolino y Fonseca.

31 "Memorias del Director de la Escuela Normal", en El Institutor, Santa Marta, 15 de marzo de 1880, No. 2. 2-7.

32 "Informe del Director de Instrucción Pública del Magdalena al Director General del Ramo", en La Escuela Normal, Bogotá 29 de marzo de 1873, 98. 
En los años siguientes, el funcionamiento irregular de la Escuela Normal del Magdalena fue una constante, muy a pesar que para el año 1875 logró ampliar el profesorado que en ella laboraba y a quienes, debido a la guerra, dejó de pagárseles por parte de la nación, lo cual llevó al Director a efectuar colectas entre las familias samarias para así garantizar que éstos continuaran al frente de sus labores. Durante los dos años siguientes, la escuela cerró sus puertas debido a la situación de orden público generado por la guerra civil, y también por las constantes epidemias que asolaban la ciudad de Santa Marta. En los informes de estos años se lee:

"No ha sido igualmente feliz la Escuela Normal en el presente año. Un doble cambio de local, verificados en enero y febrero; la epidemia de abril, y últimamente la guerra del estado, que motivó la suspensión de tareas por tres meses, causaron atrasos notables en los estudios de este año. A la pérdida de tiempo ocasionado por las causas expuestas, se agrega la falta de textos y de útiles más necesarios para la enseñanza. El Señor director conoce el rudo golpe que ha sufrido este establecimiento durante la ocupación militar; y los daños sufridos en su mobiliario, biblioteca, etc., por lo que me creo excusado al no tratar con más especialidad estos acontecimientos" ${ }^{\prime 33}$.

Loanterior da cuenta delas precariedades en medio delas cuales medianamente funcionaban las Escuelas Normales en los Estados de la región, las cuales, durante su existencia institucional debieron afrontar situaciones similares que en ocasiones obligaron a cierres periódicos que dificultaron que se alcanzaran mayores logros. Sin embargo, a pesar de los problemas afrontados las Escuelas Normales lograron formar durante el decenio de los setenta a 45 maestros, quienes, para 1882 llegaron aproximadamente a los 87 graduados; número que comparado con otros Estados como Antioquia, Cundinamarca y Santander ${ }^{34}$ resulta escaso. Pero en medio de las dificultades que aquejaban a los Estados costeños, esta cantidad resultó ser un adelanto si se compara con su propia realidad educativa, lo cual permitió a algunas escuelas primarias de la región contratar a un personal medianamente preparado para desempeñarse como maestros.

A pesar del incremento de maestros, su número continuaría siendo muy bajo con respecto a la población de los Estados costeños. Para Bolívar y Magdalena la relación de maestros por cada mil habitantes en 1870 sólo alcanzó el 0.3, cifra que a mediados de la década de los 90s se mantendría igual en el primero mientras que en Magdalena sólo llegó al 0.4, cifra que seguía siendo muy pobre frente a otros Estados como Cundinamarca y Antioquia, tal como se aprecia en el siguiente cuadro:

33 El Institutor, 5.

34 Véase: Informe del Director General de Instrucción Pública, 22. 
Cuadro No. $4^{35}$ : Número de maestros por Estados

\begin{tabular}{|lcc|}
\hline Estado & $\begin{array}{c}\text { Maestros por cada 1000 } \\
\text { Habitantes } \\
\text { 1870 }\end{array}$ & $\begin{array}{c}\text { Maestros por cada 1000 } \\
\text { Habitantes } \\
\mathbf{1 8 9 4}\end{array}$ \\
\hline Antioquia & & \\
Cundinamarca & 0.7 & 1.2 \\
Bolívar & 1.1 & 0.5 \\
Cauca & 0.3 & 0.3 \\
Magdalena & 0.6 & 0.4 \\
Santander & 0.3 & 0.4 \\
Boyacá & 0.3 & 0.4 \\
Panamá & 0.3 & 0.3 \\
Tolima & - & 0.3 \\
Total Nacional & - & 0.4 \\
\hline
\end{tabular}

La información contenida en el cuadro anterior permite ver cómo las cifras en otros Estados sufrieron un retroceso con respecto a los avances logrados en el período federal, tal como lo evidencia el caso de los Estados de Cundinamarca y Cauca, siendo Antioquia el único Estado donde el número de maestros sufrió un incremento significativo durante la Regeneración.

\section{Métodos y maestros alemanes para las Escuelas Normales}

En cuanto a los métodos utilizados en las Escuelas Normales, en éstas se aplicaron algunos de los principios de Pestalozzi, lo cual se efectuó por parte de los maestros alemanes Carlos Meisel y Julio Wallner, quienes desde su llegada a Santa Marta y Cartagena, introdujeron en estas escuelas una serie de prácticas pedagógicas propuestas por Pestalozzi para las escuelas europeas. ${ }^{36}$ A la luz de estos postulados la Escuela Normal era considerada

"[...] como el manantial de donde brotan las fuentes que fecundan el suelo donde se planta, propagando la instrucción pública. Para llenar su objeto debe a la vez. que formar hábiles y completos maestros, hacer ciudadanos que sirvan de modelo a sus semejantes y hombres que por su pureza de sus costumbres lleguen al desarrollo completo de todas sus facultades ${ }^{\prime 37}$.

Esos mismos postulados insistían en que al alumno maestro se le debía, además de dotarlo de habilidades y conocimientos propios de su profesión,

35 María Teresa Ramírez y Salazar, Irene. Surgimiento de la educación en la República de Colombia, ¿En qué fallamos?, Banco de la República, Borradores de Economía 454, (Bogotá: 2007), 27.

36 Para ver en detalle como fue la recepción de las ideas de Pestalozzi en Colombia y la aplicación de éstas en las escuelas Normales véase a Miriam Baéz Osorio. Las Escuelas Normales y el cambio educativo en los Estados Unidos de Colombia en el período Radical, 1870-1886, (Tunja: UPTC, 2004), 146.

37 AHM. "Reglamento de la Escuela Normal del Magdalena, 1873". Caja 234. 
convertirlo en ciudadano lleno de moralidad y patriotismo, lo cual pone de presente la permanencia del ideario republicano en esta institución: tenía como objetivo formar maestros que, además de reconocerse como ciudadanos, fueran un medio eficaz para la formación del nuevo hombre republicano que requería la nación.

En cuanto a los métodos allí utilizados y a la traída de maestros alemanes para aplicarlos, un cronista de la época afirmaba:

"El gobierno nos parece que ha obrado acertadamente tomando los métodos alemanes para que sean adoptados en nuestras escuelas. Bien sabemos que Alemania es la más avanzada tal vez en el ramo de la instrucción, aquella nación marcha con pasos gigantescos hacia el pedestal del progreso y de la civilización. No sería ocurrencia peregrina que por ponernos a inventar métodos dejásemos a un lado los de Alemania que tan brillantes resultados producen, como lo está demostrado la experiencia. ¿Qué método inventado por nosotros podríamos adoptar, exponiendo a perder el tiempo y a correr miles de contingencias, cuando a la verdad no hemos experimentado ninguno? Vale pues, más tener una cosa conocida y no veinte por conocer. Por otra parte no se puede ser maestro sin haber aprendido a serlo"38.

Opiniones como ésta defendían la puesta en práctica de métodos cómo el utilizado en Alemania, de donde llegaron los primeros directores de las Escuelas Normales, quienes, cómo en el caso de Meisel y Wallner, debieron aplicar estos a una realidad que distaba mucho de la alemana.

Por consiguiente, muchos de los métodos que se intentaron aplicar en las escuelas normales no alcanzaron el éxito esperado debido a diversas circunstancias, tales como los pocos recursos financieros, actitud de los alumnos y padres, poca dotación escolar, permanentes interrupciones de las actividades debido a los conflictos políticos. Circunstancias que llevaron a que la dirección de la Escuela Normal del Magdalena, en manos de Carlos Meisel, insistiera en la necesidad de ampliar la duración de los estudios de los alumnos maestros. Se insistía en que tres años no era suficientes para enseñar en buena forma cada una de las materias impartidas. $\mathrm{Al}$ respecto consideraba que

"El gran cúmulo de materias señaladas para la enseñanza en el corto tiempo de tres años, se opone a que la instrucción sea suficientemente sólida e intensiva, y esto en mayor grado, si los candidatos que se admiten de escasísimo desarrollo mentaly de muy pocos conocimientos, no reúnen las condiciones establecidas por los reglamentos, como generalmente sucede. Fácilmente se comprende que en el corto tiempo de tres años no se puede adquirir sino cierta instrucción superficial en el gran número

38 AHM. El Ferrocarril del Magdalena, Santa Marta, 29 de septiembre de 1873, No. $18,67$. 
de materias señaladas; más, si de este término el estudio se pierde una parte en vacaciones, fiestas, revoluciones y por las frecuentes enfermedades causadas por la mala situación climatérica del lugar"39.

Ante estas razones, el maestro alemán reiteraba la necesidad de ampliar a cuatro o cinco años los estudios normalistas y dar así más tiempo para la enseñanza de cada una de las materias impartidas

\begin{abstract}
"Los tres años escolares en mi concepto no son suficientes para estudiar en estos climas todas las materias reglamentarias, pues asi como el cuerpo necesita de un tiempo dado para digerir y para asimilar sus materiales, asi el espiritu necesita del suyo para aprovechar de la enseñanza y del estudio como de elementos propios para el desarrollo de sus facultades"
\end{abstract}

Al mismo tiempo se solicitaba bajar la edad de admisión de los niños a 16 años, alegándose para ello que era "[...] muy difícil encontrar jóvenes de 18 años, sin que tengan compromisos contraidos que se oponen a su ingreso en la escuela Normal."*1 Con ello se pretendía contar con maestros de mayor vocación y con una formación más sólida. $\mathrm{Al}$ mismo tiempo, que se consideraba que ya no era necesario tener una gran cantidad de maestros, sino más bien mejorar la calidad y capacidad de los mismos. Para ello se intentó hacer un seguimiento a los maestros graduados a través de la aplicación de exámenes periódicos que pudieran comprobar si éstos se mantenían actualizados en las materias que impartían en las escuelas primarias del estado.

\begin{abstract}
"Sucede generalmente que los maestros graduados continúan regentando escuelas después de haber satisfecho el compromiso que contrajeron con la Nación, y sucede también que pasando cierto tiempo después de la salida de la Escuela, no poseen los conocimientos que poseían cuando se verificó dicha salida, y esto debido al abandono en el estudio o repaso de las mismas materias que aprendieron"'².
\end{abstract}

Se pretendía entonces implementar desde la Escuela Normal un sistema de vigilancia y seguimiento al desempeño de los maestros. Ello se realizó solamente en algunas ocasiones por la poca voluntad de los Consejos Departamentales de Instrucción para hacer efectiva esta medida impulsada, como otras más, por los pedagogos alemanes. Éstos debieron enfrentarse a una realidad muy distinta a la cual estaban acostumbrados, ya que, según Santiago Pérez, director de Instrucción Pública de la Unión, aquí

\footnotetext{
39 El Institutor, 6.

40 "Informe de Carlos Meisel sobre la Escuela Normal, 1879". Santa Marta (AHM), Caja 453. Legajo II, Tomo VIII.

41 "Informe de Carlos Meisel sobre la Escuela Normal, 1879".

42 "Informe de Carlos Meisel sobre la Escuela Normal, 1879".
} 
"hay que crearlo todo, quizá no solo en luch a contra la escasez, sino también contra algunas resistencias de otro orden. Luego allá se necesita una perseverancia, una paciencia que solo el patriotismo puede mantener, y que no hay por qué exigir al maestro extranjero, cuya habilidad no implica necesariamente dichas otras cualidades" ${ }^{43}$.

Los maestros alemanes se enfrentaron también a las condiciones culturales de una población fuertemente apegada a las tradiciones y renuente a las innovaciones. Desde su llegada se encontraron con varios problemas, especialmente el poco manejo del español, la falta de textos y materiales adecuados y la desconfianza de sectores de la población por su condición de protestantes.

"Respecto del profesor alemán, señor Carlos Meisel, diré a usted francamente, que se le nota interés por la buena marcha del establecimiento; pero que la dificultad con que habla el castellano, sobre todo cuando tiene que hacer uso de los términos técnicos de alguna ciencia o arte, causará sin duda embarazo al adelantamiento de los jóvenes"'t4.

Además de las características socioculturales, los maestros alemanes se encontraron con la oposición de la Iglesia Católica, la cual se opuso a esta misión por la condición de protestantes de la mayoría de estos maestros. En tal sentido, Miguel Antonio Caro, abanderado del partido católico, encabezó la crítica contra la presencia de pedagogos alemanes traídos por el gobierno liberal. Sus razones oscilaron desde el alto costo financiero de las misiones hasta el cuestionamiento por su calidad de extranjeros, así como sus creencias religiosas distintas a las del catolicismo.

En el primero de los casos, Caro no justificaba la inversión tan alta en la Escuela Normal. Se preguntaba cómo era posible que el gobierno gastara tanto en el pago de unos muy pocos profesores que educaban a tan pocos estudiantes. Con la suma gastada en dicho instituto, señala Caro, se educaban en otras ciudades como Quito cerca de 800 alumnos $^{45}$.

Por otra parte, el político conservador echó mano del patriotismo para criticar a los radicales. De esta manera señalaba que traer alemanes al país no sería otra cosa "sino imponer el extranjerismo, acostumbrar a la servilidad,

\footnotetext{
43 “Informe del Director de Instrucción Pública de la Unión, 1872", en La Escuela Normal, Bogotá, enero 18 de $1873,46$.

44 "Informe del Secretario de Instrucción del Magdalena, Luis A. Robles", en: La Escuela Normal. 97.

45 Miguel Antonio Caro, Filosofía, Religión, Pedagogia, Obras, Tomo 1. (Bogotá: Instituto Caro y Cuervo, 1962), 1087.
} 
matar el espiritu de independencia nacional ${ }^{\$ 4}$. Además, acusó a los reformadores de contradictorios pues cuando expulsaron a los jesuitas, dentro de sus argumentos adujeron precisamente que eran extranjeros. Por último, consideró que traer a los alemanes era venerar la fuerza material expresada en la derrota que los alemanes infringieron a los franceses y confundir el protestantismo con civilización y progreso.

Que los alemanes practicaran el protestantismo, según Caro, agravaría los conflictos que vivía el país ya que, sin duda, la mayoría de la población de la Unión era católica y se podría desatar una guerra religiosa. En suma "un maestro protestante entre nosotros no puede hacer sino una de dos cosas: o atentar contra la conciencia de sus alumnos, no sin detrimento de la suya propia, o proceder contra su propia conciencia, no sin detrimento de la de sus alumnos. ¡Triste, muy triste situación!’"47.

A partir de las consideraciones anteriores, Caro se arriesgó a elaborar una propuesta económica, respetuosa de la "soberanía nacional" y católica: que los gobiernos de los Estados contrataran con los Hermanos de las Escuelas Cristianas quienes eran "verdaderamente religiosos y por lo mismo católicos, y por ende unidos, y de aquí fructíferos sus trabajos y útiles y baratos sus servicios"48.

Ante las críticas de Caro el gobierno radical respondió

"[...] los que en cuanto a la religión, no abogan por la libertad de la enseñanza sino por el monopolio a favor de ellos, han dado en Boyacáy en Cauca nuevos escándalos de fanatismo, y han llegado hasta apellidar santa la ignorancia, en contraposición a la instrucción laica que propaga el Gobierno. Si las predicaciones inmorales y las pastorales incendiarias, pueden causar algún daño, será solo transitoriamente; porque manteniéndose el Gobierno firme en el terreno constitucional en que la cuestión ha sido colocada por el Decreto, la lucha solo durará lo que la ejecución del mismo Decreto tarde en llevar hasta a los mas prevenidos la evidencia de que el actual sistema de educación popular no es una propaganda protestante. Con una sola generación que se eduque en los principios de la tolerancia, se obtendrá como resultado no que la religión de la mayoría de Colombia desaparezca de ella, resultado que no es el que la Constitución ni el Gobierno anhelan, sino el de que ni esa religión ni otra alguna sea impuesta o mantenida por la fuerza o por el fraude, $i$ el de que ni esa religión ni otra alguna sea presentada como obstáculo a la instrucción general, base de la república y de las libres instituciones [...] Cualesquiera que sean los resultados de la dirección de las Escuelas normales por profesores alemanes, los documentos de que se queja becha mención comprueban, por

46 Miguel Antonio Caro, Filosofía, Religión, Pedagogía. 1283.

47 Miguel Antonio Caro, Filosofía, Religión, Pedagogía. 1283.

48 Miguel Antonio Caro, Filosofía, Religión, Pedagogía. 1284. 
una parte, que lo que se propuso el Gobierno que los hizo venir, fue exclusivamente mejorar la educación popular, y no atacar culto religionario ninguno; y por otra parte, que el mismo Gobierno tomó cuantas precauciones podían aconsejarle el patriotismo y la prudencia"*s.

Una vez rechazada la propuesta de Caro, los Estados procedieron a ubicar a los pedagogos alemanes. La necesidad de traer profesores europeos la propuso en 1871 la Asamblea del Estado soberano del Magdalena en la cual se presentó un proyecto de acuerdo "para hacer venir de Alemania un instructor para la enseñanza primaria del distrito", al cual debían pagar cerca de 800 pesos anuales que se hacían poco, según los diputados, por "ser un elemento civilizador reclamado ingentemente ${ }^{50}$.

Esta idea se concretó en el año de 1872, cuando fueron contratados los alemanes Karl Meisel para dirigir la escuela del Estado del Magdalena y Julio Wallner como director de la Escuela Normal de Bolívar.

Para el Secretario General del Estado del Magdalena, los maestros alemanes eran fundamentales para continuar avanzando en la Instrucción Pública. Al respecto consideraba:

"Comprendiendo el ciudadano presidente que una de las primeras necesidades en este asunto, era la de adquirir hábiles Institutores que pudieran con provecho regentar las escuelas, ha dirigido sus mejores esfuerzos a comunicar un impulso riguroso al establecimiento de la Escuela Normal, que servida como está por personas competentes en todo sentido, es de esperarse se obtengan jóvenes instruidos y pedagogos idóneos, que terminado el tiempo de su aprendizaje, pasen a regentar las escuelas" $" 51$.

Cada maestro alemán aceptó recibir por parte de la nación 1200 pesos anuales, a la vez que firmaron un contrato de trabajo por 6 años, el cual se inició en 1872. En el caso de Karl Meisel, el cónsul colombiano en Berlín justificaba su vinculación dado sus capacidades y conocimientos ya que enseñaba a través del "método prusiano, ó método de enseñanz̧a pestalozziano con moralidad pública", agregando que "tiene habilidad pedagógica, conocimientos científicos y conducta privada, las mejores calificaciones, asi de la Escuela Normal donde se educó, como de los directores de las escuelas en las que han estado enseñando' ${ }^{52}$.

\footnotetext{
49 "Informe del Director de Instrucción Pública de la Unión, 1872", en La Escuela Normal, Bogotá, enero 18 de $1873,49$.

50 A.H.M. 1871. Cajá $\mathrm{N}^{\circ}$ 8. s.f.

51 A.H.M. 1873. Cajá $\mathrm{N}^{\circ}$ 9. s.f.

52 A.H.M. 1871 Cajá $\mathrm{N}^{\circ}$ 6. s.f.
}

Rev. hist.edu.latinoam - Vol. 14 No. 18, enero-junio 2012 - ISSN: 0122-7238 - pp. 155 - 182 
Meisel, quien había nacido en Brynek, arribó a Santa Marta en Febrero de 1872 encontrando condiciones adversas a la creación de la Normal y a su estabilidad laboral. El primer problema que afrontó fue la falta de espacio físico para la escuela y para albergarse. Ante sus quejas el Secretario General del Estado advertía "no está en mis manos facultades para proporcionar el edificio en que ha de establecerse la escuela mencionada" 53 .

A pesar de estos inconvenientes se logró conseguir el edificio y poner en funcionamiento la escuela a finales de 1872. Las matrículas se abrieron en Enero de 1873, seleccionándose el estudiantado y aprobándose su reglamento. Después de evaluar los libros y la forma como se administraba la enseñanza en la ciudad de Santa Marta, Karl Meisel inició con los alumnos de la escuela anexa su programa de estudios el cual, comparado con el que se impartía hasta 1872, presentaba importantes y notables adelantos. Para ello, Meisel se apoyó en textos y libros aprobados por el gobierno central y recomendados por el jefe de instrucción pública.

Escogidos los textos, en su plan de estudios incluyó materias nuevas combinándolas con las ya existentes en el currículo educativo local. Las materias que empezaron a recibir los estudiantes de la Escuela Normal en jornada continua fueron: "Aritmética, pedagogía, historia, lectura, física, historia natural, geografía, dibujo, ejercicio de composición, gimnasia, geometría, francés, canto, escritura e historia patria ${ }^{\prime 54}$. Estas se impartían en dos jornadas, de 7 a.m a $12 \mathrm{~m}$ y de 2 p.m a 4 p.m.

La escuela garantizaba a los estudiantes y profesores, vivienda, alimentación diaria y útiles escolares. Por otro lado, como ya anotamos, Meisel constantemente se quejaba por los elementos que obstaculización su labor, entre los que se cuenta el poco interés de los jóvenes por la pedagogía, el bajo nivel educativo, la oposición de la Iglesia católica y los constantes conflictos políticos y militares entre los radicales y los conservadores.

Al parecer el conflicto con la Iglesia logró disminuir un poco gracias a la actitud conciliadora y pragmática de Meisel, quien en 1875 cedió ante el obispo de Santa Marta, José Romero, quien desde el pulpito se oponía a las labores de la Escuela Normal, para lo cual acusaba a sus directores de ateos y anticatólicos, porque habían aceptado la "ley 191 del 16 de Diciembre de 1872 que prohíbe en su artículo 56 a los directores y a los ministros de culto

53
A.H.M. 1872 Cajá $\mathrm{N}^{0}$ 4. s.f.
A.H.M. 1872 Cajá $\mathrm{N}^{0}$ 4. S.f. 
enseñar la religión en los recintos de la escuela, creo que la escuela normal con sus anexos, regidos por reglamentos especiales, no están comprendidos en la ley citada [...]"55. Para apaciguar al Obispo Romero, el maestro alemán terminó por aceptar que en la Escuela Normal se impartiera la cátedra de "lecciones de Instrucción Moral y Religiosa", con lo cual aspiraba a disminuir el ausentismo de alumnos cuyos padres preferían no enviarlos para evitar las críticas e intimidaciones del obispo Romero, quien amenazaba con excomulgar a quien enviara a sus hijos a la escuela pública.

El pragmatismo de Meisel permitió, aún en medio de las penurias fiscales y las críticas de algunos otros sectores de la sociedad samaria, el funcionamiento más o menos regular de la Escuela Normal, labor que fue reconocida por la prensa local:

"El señor Meisel, que sabe suministrar los conocimientos de la Ciencia que posee, tiene la admirable facilidad de hacerse respetar de sus discípulos por cariño y no por temor. Algunos años hace que el señor Meisel cumplido caballero, Director de la Escuela Normal de varones de esta ciudad, presta lucidamente sus servicios a la instrucción pública, como se ha notado del resultado de los exámenes, satisfactorio a todas las exigencias y tenemos alumnos maestros, graduados en su establecimiento, que en la actualidad desempeñan bien los puestos de institutores en varias escuelas del estado. De suerte que sus esfuerzos en instruir la juventud colombiana, según el método objetivo, se ha ramificado provechosamente, puesto que sus discipulos contribuyen con él en la difusión de las luces dentro y fuera del estado"

Cómo ya vimos, a pesar de sus esfuerzos, Meisel no pudo impedir los varios cierres de la Normal a causa de las guerras civiles y por los problemas financieros del Estado. Al final, el proyecto formador iniciado por Meisel sólo duraría hasta 1879 cuando los radicales perdieron el poder y la alianza entre conservadores, nuñistas y la Iglesia católica impuso su proyecto educativo, lo cual obligó a Meisel y su esposa a trasladarse en 1881 a Barranquilla, ciudad que para ese entonces era más abierta a las ideas y proyectos modernizadores europeos, como los que pudo ejecutar allí Meisel a través de la fundación de varias instituciones educativas, entre las cuales se destacan el colegio Ribon el cual abrió sus aulas en 1881 .

En cuanto a Julio Wallner, otro de los maestros alemanes que llegó a la costa Caribe en la misión pedagógica contratada por el gobierno nacional, su labor como director de la Escuela Normal de Bolívar sólo fue hasta 1878, año en el cual terminó su contrato. Por ello fue reemplazado por Antonio

55 A.E.M. 1875. Tomo 108 folio 345.

56 El Correo de la Costa. Santa Marta, 5 de febrero de 1878. No. 4, 14. 
Cátula Royo. Pero a Wallner le correspondió la labor de organizar y orientar la Escuela Normal en medio de las dificultades económicas y la resistencia de orden cultural y político de quienes consideraban que la escuela atentaba contra los valores católicos de los estudiantes.

Desde su arribo a Cartagena, Wallner advertía al director de instrucción pública del Estado de Bolívar la necesidad de que la Escuela Normal contara con los libros pertinentes para poder inculcar en los alumnos-maestros las ideas de Pestalozzi, al mismo tiempo que se quejaba del escaso número de jóvenes interesados en seguir la carrera de maestros. Para 1879, la Escuela Normal sólo había logrado graduar a 26 maestros, de los cuales 16 se vincularon como maestros en las escuelas públicas del Estado, otro hacia parte de los funcionarios adscritos a la Dirección de Instrucción Pública, mientras otro se había residenciado en la Isla de San Andrés y otro había fallecido. Los siete restantes se encontraban cesantes.

A pesar del bajo número de maestros formados en las Escuelas Normales establecidas en los Estados costeños, es necesario tener en cuenta la importancia que durante el periodo federal se le reconoció al maestro. Entendido éste como un sujeto portador de virtudes y valores que servían de ejemplo a niños y jóvenes que asistían a la escuela a recibir los fundamentos básicos para transitar hacia la ciudadanía. En tal sentido a los maestros alemanes se les consideró como ejemplos a imitar por parte de quienes se formaban como maestros en las Escuelas Normales. Razón por la cual la prensa de la época realizó una apología de personajes como Karl Meisel y Julio Wallner destacando supuestas virtudes y capacidades morales de estos pedagogos alemanes. Éstos terminaron involucrados en un proceso impulsado desde el gobierno radical a través del cual se buscaba la formación de un cuerpo laico de institutores como un paso primordial para garantizar la formación ciudadana desde la escuela republicana.

\section{CONCLUSIÓN}

La representación de la imagen del maestro como figura pública se constituyó entonces en un indicador del reconocimiento y existencia de esta profesión durante el período federal. La misma que desde inicios del siglo XIX había dejado de ser sólo un oficio para transitar hacia su profesionalización. Este proceso contribuyó la creación, por parte de los gobiernos radicales, de las Escuelas Normales. Es decir, a pesar de que en algunas escuelas públicas seguían ejerciendo los viejos maestros que hacían parte del gremio profesoral, la labor de maestro, independientemente de las razones por las cuales se llegó 
a ella, era ya una profesión que desde inicios del período federal estaba, por lo menos formalmente, bajo el control del Estado.

\section{FUENTES}

\section{Archivos}

Archivo Histórico de Cartagena, Fondo de Prensa siglo XIX.

Archivo Histórico del Atlántico, Fondo de Prensa siglo XIX.

Archivo Episcopal de Santa Marta. Pastorales e informes 1850/1889.

Archivo Histórico del Magdalena, Informes de Instrucción Públca, 1857/1879.

Biblioteca Luis Ángel Arango, Hemeroteca.

Biblioteca Nacional de Colombia, Libros antiguos, raros y curiosos del siglo XIX.

\section{Periódicos}

Diario de Bolivar, Cartagena, 1875- 1881.

El Promotor, Barranquilla, 1871-1899.

Gaceta del Estado de Bolivar, Cartagena, 1860-1870.

Gaceta del Estado del Magdalena, Santa Marta, 1860-1878.

La Escuela Normal, Bogotá, 1871-1879.

La Revista, 1872-1874.

El Institutor, Santa Marta, 1872.

\section{Disposiciones legales e informes}

Decreto Orgánico de de la Instrucción Pública Primaria, Bogotá, Imprenta de la Nación, 1870.

Disposiciones Vigentes sobre Instrucción Pública Primaria, Cartagena, Tipografía de Antonio Araujo, 1886.

Disposiciones vigentes sobre Instrucción Pública Primaria, Cartagena, Tipografía Araujo, 1886.

Leyes y Decretos del Estado Soberano del Magdalena, 1857-1867, Bogotá, Imprenta Foncion Mantilla, 1869.

Leyes del Estado Soberano del Magdalena, 1872-73, Imprenta El Ferrocarril del Magdalena, Santa Marta, 1874.

Leyes del Estado de Bolívar 1872, Tipografía Araujo, 1872.

\section{REFERENCIAS}

Ahern, Evelyn. "Desarrollo de la educación en Colombia (1820-1850)". Revista Colombiana de Educación, No. 22-23, (1991), 78.

Alarcón Meneses, Luis, y Conde, Jorge, Educación y cultura en el Estado Soberano del Magdalena, Barranquilla: Ediciones Universidad del Atlántico, 2002.

Alarcón Meneses, Luis. Legislar para gobernar. La normatividad educativa en el Estado Soberano del Magdalena, Stvdia, No.1, (2002): 38-57.

Álvarez Gallego, Alejandro, ...Y la escuela se biẓo necesaria. Bogotá: Magisterio, 1995. 
Caro, Miguel Antonio. Obras. Tomo 1. Filosofía, Religión, Pedagogía. Bogotá: Instituto Caro y Cuervo. 1962.

Chartier, Roger. El Mundo como representación. Historia cultural: entre práctica y representación. Barcelona: Gedisa. 1996.

De Puelles Benitez, Manuel. Estado y Educación en la España Liberal 1809-1857. Barcelona: Pomares, 2004.

Escolano Benito, Agustín. Tiempos y espacios para la escuela. Ensayos históricos. Madrid: Biblioteca Nueva, 2000.

Escolano, Benito. "Memoria del currículum y formación de maestros", en: IV Jornadas de teorías e instituciones educativas contemporáneas, edt. por Argos, Javier y Ezquerra $\mathrm{M}^{\circ}$ Pilar, Santander: Universidad de Cantabria. 1999.

Fröebel, Federico, La Educación del Hombre, Nueva York: Appleton, 1885.

Helg, Aline. La Educación en Colombia 1918-1957, Bogotá: Cerec, 1978.

Jaramillo Uribe, Jaime. "Elproceso de la educación en la República (1830-1886)", en: Nueva Historia de Colombia, Vol. II, Bogotá: Colcultura, 1980.

Lane Young, Jhon. La reforma universitaria de la Nueva Granada, Bogotá: UNPN-ICC, 1999.

Loaiza Cano, Gilberto. "El maestro de la escuela o el ideal liberal del ciudadano en la reforma educativa de 1870”, Historia Crítica, No. 34, (2007), 60.

Murillo Toro, Manuel Obras selectas, Bogotá: Colección Pensadores Políticos Colombianos, Cámara de Representantes. 1979.

Prieto Figueroa, Luis. El Estado y la educación en América Latina. Caracas: Monte Ávila, 1990

Quijada, Mónica (et.al), Homogeneidady Nación, Madrid: CSIC. 2000.

Rausch, Jane. La Educación durante el federalismo. Bogotá: Instituto Caro y Cuervo. 1993.

Saldarriaga, Oscar. "Gramática, Epistemología y Pedagogía en el siglo XIX: La polémica colombiana sobre los elementos de ideología de Dessttut De Tracy -1870-“, Memoria y Sociedad, No. 17. (2004).

Sierra Mejia, Rubén (Editor). El radicalismo colombiano del siglo XIX. Bogotá: Universidad Nacional de Colombia. 2008.

Viñao, Antonio. Sistemas educativos, culturas escolares y reformas. Madrid: Morata, 2002.

Zuluaga, Olga Lucía y OSSENBACH, Gabriela, Génesis y desarrollo de los sistemas educativos iberoamericanos siglo XIX. Bogotá: Colciencias, 2004.

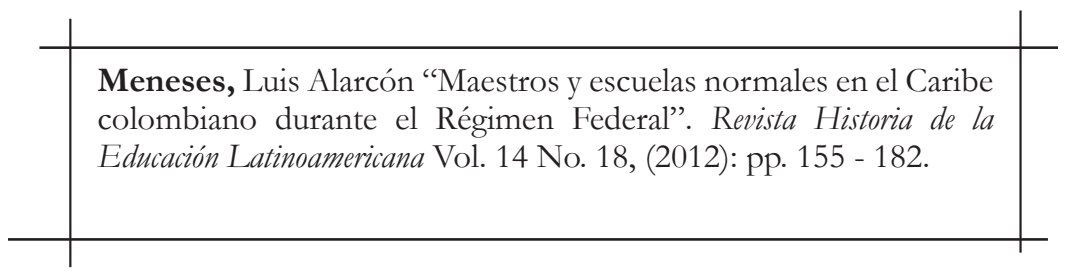

